\title{
AC 2011-1273: ASSESSING ENGINEERING STUDENTS' INFORMATION LITERACY SKILLS: AN ALPHA VERSION OF A MULTIPLE-CHOICE INSTRUMENT
}

\section{Ruth E. H. Wertz, Purdue University, West Lafayette}

Ruth E. H. Wertz is a graduate student in Engineering Education at Purdue University. She is a Professional Engineer in the State of Indiana, and holds BS and MS degrees in Civil Engineering from Trine University and Purdue University.

\section{Meagan C Ross, Purdue University, West Lafayette}

Meagan Ross is a Ph.D. student in the College of Engineering Education at Purdue University. She received a B.S. in Computer Science from Texas Woman's University, and a M.S. in Electrical Engineering from Texas Tech University. Prior to beginning her doctoral studies, she worked as a micro-optoelectromechanical systems engineer for Texas Instruments. Meagan began working for Institute for P-12 Engineering Research and Learning (INSPIRE) in the area of teacher professional development in 2009. Meagan is passionate about providing awareness of engineering to K-12 teachers \& counselors so that they can inform and advocate this important career to their students. Her research interests include gender equity in the K-12 Classroom, assessment of K-12 engineering education, curriculum development, and teacher professional development.

\section{Senay Purzer, Purdue University, West Lafayette}

Purzer is an Assistant Professor in the School of Engineering Education and is the Co-Director of Assessment Research for the Institute for P-12 Engineering Research and Learning (INSPIRE) at Purdue University. Purzer has received her M.A. and Ph.D. degrees in Science Education at Arizona State University. She has a B.S. degree in Physics Education and a B.S.E. in Engineering. She has journal publications on instrument development, teacher professional development, and K-12 engineering education. Her creative research focuses on design problem-solving, collaborative learning, and assessment research.

Michael Fosmire, Purdue University Libraries, West Lafayette

Monica E Cardella, Purdue University, West Lafayette

Monica E. Cardella is an Assistant Professor of Engineering Education and is the Co-Director of Assessment Research for the Institute for P-12 Engineering Research and Learning (INSPIRE) at Purdue University. Dr. Cardella earned a B.Sc. in Mathematics from the University of Puget Sound and an M.S. and Ph.D. in Industrial Engineering at the University of Washington. At the University of Washington she worked with the Center for Engineering Learning and Teaching (CELT) and the LIFE Center (Learning in Informal and Formal Environments). She was a CASEE Postdoctoral Engineering Education Researcher at the Center for Design Research at Stanford before beginning her appointment at Purdue. Her research interests include: learning in informal and out-of-school time settings, pre-college engineering education, design thinking, mathematical thinking, and assessment research. 


\title{
Assessing Engineering Students' Information Literacy Skills: An Alpha Version of a Multiple-Choice Instrument
}

\begin{abstract}
Information literacy is crucial component of developing life-long learning skills. However, few standard and easily gradable assessment tools exist to assess the information literacy competencies of learners. In this paper, we discuss the development of a multiple choice instrument designed to measure these competencies in an efficient and expedient manner, and we present results of data collected from 366 first-year engineering students. The instrument requires students to first read a technical memo and, based on the memo's arguments, answer eight multiple choice and two open-ended response questions. The mean score on the multiple choice portion was only 3.46 out of 8 . A qualitative analysis of the open-ended responses provided more insights into students' abilities to identify and resolve conflicts between information sources, evaluate the reliability and relevancy of information sources, and use reliable information sources.
\end{abstract}

\section{Introduction}

One of the most important skills students can take away from a technical education is the ability to become curious, persistent, and life-long learners, and information literacy is crucial to developing those skills. For example, Shuman, et al, when describing requirements for lifelong learning, explicitly includes informational components, expecting students will

- Demonstrate reading, writing, listening, and speaking skills

- Demonstrate an awareness of what needs to be learned

- Follow a learning plan

- Identify, retrieve, and organize information

- Demonstrate critical thinking skills

- Reflect on one's own understanding'.

There is substantial overlap between Shuman's lifelong learning competencies and those identified by the Association of College and Research Libraries in their Information Literacy Competency Standards, which include

- Determining the extent of information needed

- Access the needed information effectively and efficiently

- Evaluate information and its sources critically

- Incorporate selected information into one's knowledge base

- Use information effectively to accomplish a specific purpose

- Understand the economic, legal, and social issues surrounding the use of information, and access and use information ethically and legally. ${ }^{3}$

Despite the growing importance of lifelong learning skills in our rapidly evolving work environment, where technical knowledge has a half life of less than five years, Lattuca, Terenzini, and Volkwein reports that students assess their lifelong learning skills as the lowest of 
all the 'category 3' student outcomes, with almost no improvement in those scores in the past ten years ${ }^{2}$. With regard to information literacy specifically, recent studies have found students skip steps in the research process ${ }^{3}$, and have a substantial overreliance on internet search engines ${ }^{4}$ and web sites of marginal quality ${ }^{5-7}$

\section{Development of Information Literacy Assessment Tool}

Despite the growing importance of lifelong learning, few standard and easily gradable assessment tools exist to assess the information literacy components of lifelong learning skills, especially in the context of an engineering education. iSkills ${ }^{8}$ requires students to carry out a task, such as organizing e-mails, but is expensive and takes a long time to administer, which are often non-starters for educators. The Information Literacy Test (ILT), is another multiple choice test that focuses on knowledge-level performance of students, rather than assessing processes students use ${ }^{9}$. Existing instruments generally involve self-reports rather than objectively measuring life-long learning skills ${ }^{10}$. We developed a multiple choice instrument to measure students' information literacy skills and not perceptions. The instrument included a technical memo on the top and asked students to answer eight multiple choice and two open-ended response questions based on the memo's arguments. The memo was authentic and included errors as it was written based on actual memos written by first-year engineering students.

The technical memo proposed a method that would provide energy savings for the University Residence Halls (see Appendix). This memo included proposed solutions as well as information and citations (websites, blog, published scholarly literature, and informal interviews) used to support the argument made by the author. A table included in the memo also calculated potential savings for the Residence Halls.

In this paper, we present results from the multiple choice instrument and provide an evaluation of students' information literacy competencies. Using the ILCS framework, objectives for this instrument were designed to assess if students can identify implicit and explicit assumptions, identify and resolve conflicts between information sources (including pre-existing knowledge), evaluate the reliability and relevancy of information sources and use reliable information sources, accurately acknowledge the sources referenced, evaluate overall quality of a written document, determine what is known and what new information is needed to make a strong argument, extract the main points from the information sources and critically evaluate and integrate information from a variety of sources.

\section{Method}

\section{Sample and Setting}

Participants in the study were 366 first-year engineering students during their first semester in college. As part of an in-class assignment students were given the assessment which included a memo and questions related to the content of this memo. The study was conducted in the context of a foundation course at a large Midwestern university, which all freshman engineering students take. Students were required to complete the assessment as a part of the course. The assessment was administered online and students were allowed access to the internet to refer to the sources listed in the memo if they so desired. 


\section{Procedure}

Students are asked to read the memo and, based on its arguments, answer eight multiple choice questions and complete two open ended responses. The multiple choice questions have either 4 or 5 possible choices, with only one correct answer. The two open ended response questions are related to two different multiple choice questions. The questions are targeted to address student objectives which are defined by the concepts the researchers were targeting to assess.

\section{Data Analysis}

We conducted an item analysis of the multiple choice questions along with an examination of two open-ended items. The KR-20 reliability coefficient of the multiple choice items was .34.

\section{Results}

The analysis of the two-tier assessment focused on the primary information literacy concepts discussed above. The eight multiple choice questions were graded based on correctness. Rather than grading the open ended responses for correctness, the data was qualitatively analyzed to determine themes in student response.

\section{Overall Scores of the Multiple Choice Test}

The mean score for the eight-question multiple choice assessment is $3.46(\mathrm{SD}=1.50)$. Only one student in the sample answered all questions correctly. One question, "What is the main point of this memo?" had a $91 \%$ correct response rate, while the remaining questions fell between $16 \%$ and $48 \%$ correct response.

\section{Item Difficulty and Discrimination Index}

Item difficulty (p-value) is determined by calculating the proportion of students that answered the item correctly. The p-value ranges between 0 and 1 . While lower values indicate high item difficulty, a p-value of 1 indicates all students answered the question correctly.

The point-biserial correlations on the other hand provide information on how well the item discriminates between high achieving and low achieving students by correlating a student's overall test score and score on a specific item. The Point-biserial correlations provide information on an item's discrimination and is the correlation between a students' score on a given item and his or her overall score. We reported the corrected item-total correlations. The point-biserial values range between -1 and +1 and a value of at least 0.15 is preferred.

In general, tests are more reliable if the items varied with regard to their item difficulty but had high item discrimination values. An analysis of item difficulties showed that Question 4 and Question 9 were well-written as they had moderate level of difficulty and item discrimination. Question 10 was a very easy item with poor discrimination score. Question 2 and Question 8 had low p-values indicating they were difficult items. Question 2; however, was better at discriminating between high and low achieving students compared to Question 8.

Overall, the poorest items in the assessment were Question 8 with high difficulty and low discrimination and Question 10 with low difficulty and low discrimination. 
Table 1. Item Difficulty and discrimination

\begin{tabular}{l|cccccccc}
\hline $\begin{array}{l}\text { Item Difficulty } \\
\text { (p-value) }\end{array}$ & Q1 & Q2 & Q4 & Q6 & Q7 & Q8 & Q9 & Q10 \\
$\begin{array}{l}\text { Point-biserial } \\
\text { Correlations }\end{array}$ & 0.48 & 0.16 & 0.46 & 0.33 & 0.45 & $\mathbf{0 . 1 6}$ & 0.51 & $\mathbf{0 . 9 1}$ \\
\hline
\end{tabular}

Item Response Patterns \& Open-ended Response Questions

The analysis of item responses and the examination of students' answers to the open-ended questions provided information on how students answered each question. Table 2 shows the percentage of students who selected a specific answer. Two questions in the assessment were open-response to a previous multiple choice question. These two questions are discussed in detail.

Table 2. Item Response Patterns

\begin{tabular}{l|rrrrrrrr} 
Option & \multicolumn{1}{c}{$\mathrm{Q} 1$} & \multicolumn{1}{c}{$\mathrm{Q} 2$} & \multicolumn{1}{c}{$\mathrm{Q} 4$} & \multicolumn{1}{c}{$\mathrm{Q} 6$} & \multicolumn{1}{c}{$\mathrm{Q} 7$} & \multicolumn{1}{c}{$\mathrm{Q} 8$} & \multicolumn{1}{c}{$\mathrm{Q} 9$} & $\mathrm{Q} 10$ \\
\hline $\mathrm{A}$ & $13.9 \%$ & $13.4 \%$ & $3.4 \%$ & $10.9 \%$ & $\mathbf{4 5 . 2 \%}$ & $6.1 \%$ & $13.2 \%$ & $1.7 \%$ \\
$\mathrm{~B}$ & $3.8 \%$ & $\mathbf{1 6 . 2 \%}$ & $4.0 \%$ & $16.2 \%$ & $8.4 \%$ & $\mathbf{1 5 . 6 \%}$ & $\mathbf{5 0 . 8 \%}$ & $2.5 \%$ \\
$\mathrm{C}$ & $33.4 \%$ & $9.2 \%$ & $\mathbf{4 6 . 0 \%}$ & $\mathbf{3 3 . 2 \%}$ & $8.4 \%$ & $14.1 \%$ & $8.8 \%$ & $2.3 \%$ \\
$\mathrm{D}$ & $\mathbf{4 7 . 9 \%}$ & $58.8 \%$ & $41.0 \%$ & $4.4 \%$ & $35.5 \%$ & $61.8 \%$ & $7.1 \%$ & $\mathbf{9 0 . 8 \%}$ \\
$\mathrm{E}$ & $\mathrm{n} / \mathrm{a}$ & $\mathrm{n} / \mathrm{a}$ & $4.4 \%$ & $33.2 \%$ & $\mathrm{n} / \mathrm{a}$ & $\mathrm{n} / \mathrm{a}$ & $17.2 \%$ & $1.1 \%$ \\
\hline
\end{tabular}

Note: Correct answers are shown in bold.

\section{Question 2}

Only $16 \%$ of students answered question two (Figure 1) correctly, and only $6 \%$ of the corresponding open-ended responses (Question 3) were correct. We then examined why students chose their answers to this question by looking at their responses to the open-ended questions. Representative responses are included in Figure 1. In these questions, we probed students' ability to understand, evaluate and appropriately use information they find. We found that students were generally unfamiliar with the wattage of a conventional light bulb, or at least didn't question the number used in the memo, nor, apparently the corresponding result that it costs \$2000 a year to light one light bulb. Standard three of the ACRL Information Literacy competencies require that a student "evaluates information and its sources critically and incorporates selected information into his or her knowledge base and value system." Despite giving the students several clues (improper wattage, confusion of power and energy, unreasonable utility costs for a light bulb), students did not critically evaluate whether the information provided in the memo was correct or not. Also, we found that most students who answered Question 2 correctly did so for superficial and incorrect reasons, rather than because they understood the correct reasoning.

Instead, it appeared most students fixated on the comparison of the energy consumed by lighting compared to refrigerators, noting that refrigerators were not the focus of the memo, and this led to the incorrect choice of D by the majority of students. In this case students did not distinguish information that appeared in the memo that was inaccurate with information that didn't appear in 
the memo that may or may be accurate. It indicates improper interpretation of the question, which explicitly refers to 'the following statements used in the memo' [author's emphasis added.] Students appeared to prefer guessing that the refrigerator might use more energy than using their knowledge of conventional electricity usage to arrive at the correct answer.

Figure 1. Question 2 as it appears in assessment tool

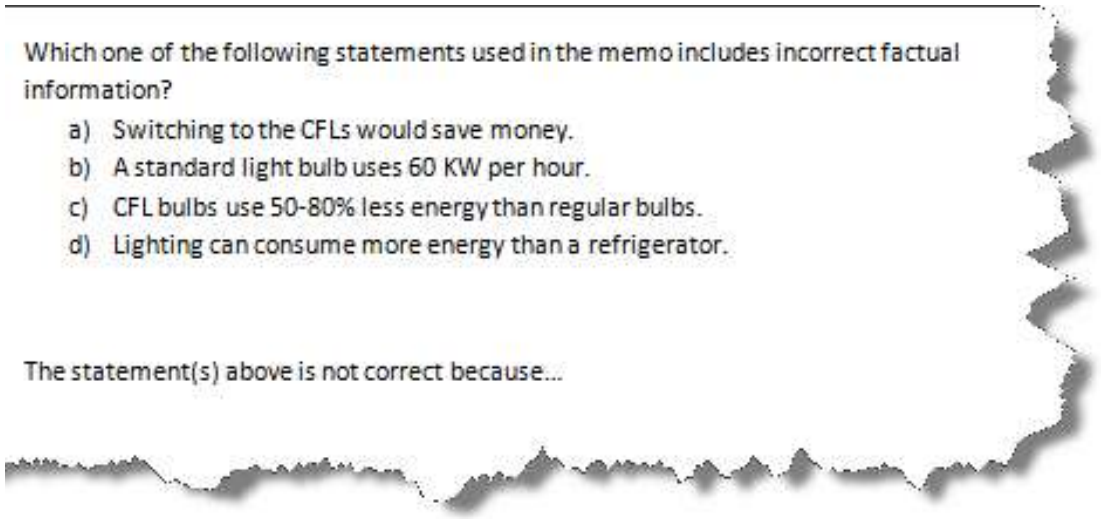

\begin{tabular}{|c|c|c|}
\hline Option & Q2 & Reponses to Open-ended Question \\
\hline $\mathrm{A}$ & $13.4 \%$ & $\begin{array}{l}\text { "No facts included" } \\
\text { "The cost in the long run might not save money" } \\
\text { "There is the cost of replacing the incandescent bulbs that also has to be } \\
\text { added. So, }(\$ 5 * \text { no. of bulbs being changed })+2000 \text { would offset the } \\
\text { savings of } \$ 2760 . " \\
\text { "It would reduce energy consumption and not reduce cost." }\end{array}$ \\
\hline B & $16.2 \%$ & $\begin{array}{l}\text { "It's completely wrong in the unit. It should be KWh, not KW. A } \\
\text { standard light bulb is } 100 \mathrm{~W} \text {, which means it uses } 0,1 \mathrm{KWh} \text { per hour." } \\
\text { "There is no such thing as a "Standard" light bulb because standards are } \\
\text { relative." } \\
\text { " } 60 \mathrm{kw} \text { bulbs are in no way the standard. There are multiple types of } \\
\text { bulbs that could potentially be used such as } 49 \mathrm{kw} \text { or } 80 \mathrm{kw."}\end{array}$ \\
\hline $\mathrm{C}$ & $9.2 \%$ & $\begin{array}{l}\text { "This statement uses incorrect factual information because the } \\
\text { percentage was different between each source that stated the } \\
\text { percentage." } \\
\text { "It depends on how large bulbs work at the same time." } \\
\text { "The statement is incorrect because it is based on unidentifiable or } \\
\text { unreliable sources." } \\
\text { "the range } 50-80 \% \text { is too broad and incorrect." }\end{array}$ \\
\hline $\mathrm{D}$ & $58.8 \%$ & $\begin{array}{l}\text { "It doesn't sound right." } \\
\text { "Refrigerator has never been mentioned in the article." } \\
\text { "A refrigerator is always running, but the lightbulbs are on only about } \\
\text { five hours a day." } \\
\text { "there is no data to back up this claim." }\end{array}$ \\
\hline
\end{tabular}




\section{Question 4}

Forty-six percent of students answered Question 4 (Figure 2) correctly, and of those with the correct answer, 95.6\% also provided an appropriate corresponding open response, that the source was a personal blog, the author had no discernable credentials, and there were no other external ways to validate the authority or reliability of the content. Again, representative student responses are included in the Figure 2, and unlike Question 2, we note that the majority of correct responses to Question 4 were based on correct reasoning. Some students chose option ' $a$ ', just because it was a commercial web site. However, the information gathered from the web site was merely the local electricity rate, and the utility should be the best source of that information. Some students apparently had been taught that commercial web sites are intrinsically unreliable, and thus used an oversimplified heuristic to dismiss the information from that source.

Most students with the incorrect answer believed that interviews of students were unreliable. This was, perhaps, understandable. Some students suggested that there were better ways to derive that information (for example, from sensors or someone working in the physical plant), while most just didn't believe that students were credible sources of information, or that the memo authors were credible data gatherers. We included this option in the assessment because we believed engineering students in particular might not be comfortable with qualitative research methods compared to direct observations, and our assumption was validated to a degree. Although the student observations were quite interesting, it appears that including the interview option was too distracting for many students, so in future versions of the assessment, that option will be deleted.

Figure 1. Question 4 as it appears in assessment tool

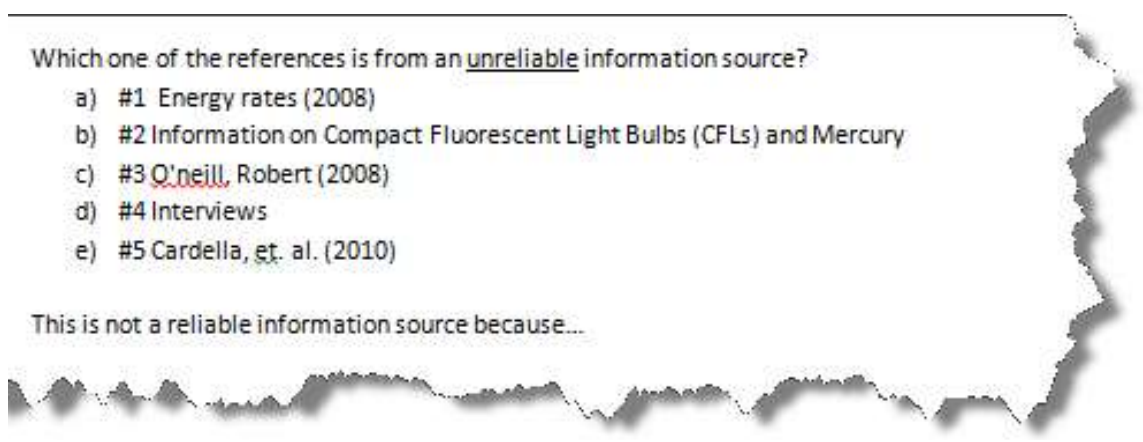

\begin{tabular}{l|ll} 
Option & Q4 & \multicolumn{1}{c}{ Reponses to Open-ended Question } \\
\hline A & $3.4 \%$ & $\begin{array}{l}\text { "It comes from a ".com" URL." } \\
\text { "energy rate is not an accurate number." } \\
\text { "There is no author. It is a commercial website." }\end{array}$ \\
$4.0 \%$ & $\begin{array}{l}\text { "The source is doubtful as in that they are trying to sell something } \\
\text { through promotions." } \\
\text { "It does not have a year following the information." } \\
\text { "There's not an author or a copyright. The site isn't even } \\
\text { presentable. It looks like they copy-and-pasted the energy star logo } \\
\text { on their site." }\end{array}$
\end{tabular}




\begin{tabular}{|c|c|c|}
\hline $\mathrm{C}$ & $46.0 \%$ & $\begin{array}{l}\text { "it is a blog" } \\
\text { "Random guy. Random blog." } \\
\text { "It's just a person that I've never heard of so I decided that it's } \\
\text { probably not a reliable source." } \\
\text { "This source does nothing to establish its credibility and does not } \\
\text { cite its sources for its information." }\end{array}$ \\
\hline $\mathrm{D}$ & $41.0 \%$ & $\begin{array}{l}\text { "There are so many students in a dorm. We can not use them as a } \\
\text { reliable source." } \\
\text { "There's no specific and enough information about the interviews } \\
\text { with the dorm students. How they were carried out, how big is the } \\
\text { data base and related important information are not provided." } \\
\text { "it does not have a date." } \\
\text { "everyone in dorms has different amounts of electricity usage." } \\
\text { "Some students might be lying or don't actually know the amount } \\
\text { of time their lights are on." }\end{array}$ \\
\hline $\mathrm{E}$ & $4.4 \%$ & $\begin{array}{l}\text { "Her first year engineering courses could not provide enough } \\
\text { persuasive information." } \\
\text { "It is education material, not for practical uses." }\end{array}$ \\
\hline
\end{tabular}

\section{Discussion}

The results of this multiple-choice assessment indicate that first-year engineering students possess weak information literacy skills. However, there is also need to revise some of the items to increase the reliability of the instrument and the discrimination index of the items. The low achievement scores (mean=3.46; standard deviation=1.50) on the 8 multiple choice questions suggest that further instruction on information literacy is needed for students to adequately develop these skills. While many students used appropriate vocabulary in their openended responses (i.e. biased, credibility, variability, assumptions), it was often misguided by their corresponding multiple choice response. For the first open response question, students wrote that they chose D because 'refrigerator' was never mentioned in the memo. This indicates that the multiple choice options or the phrasing of the question needs to be revised in order to effective measure the concept. For the second open response question, students who answered D, the student interviews, as the most unreliable source, $92 \%$ of those students gave an adequate rationale using the vocabulary associated with information literacy skills. With further instruction about qualitative research, to which few engineering students are currently exposed, students would potentially be less likely to choose this response. Within the context of engineering, this might be accomplished through instruction on user-centered or human-centered design, interaction design, or usability testing. 


\section{Conclusion}

The qualitative responses support the quantitative scores: information literacy skills among firstyear engineering students need to improve for students to develop information literacy skills important to become competent lifelong learners. Additionally, the qualitative results provided insights into some of the specific misconceptions or deficiencies students have related to information literacy skills. The quasi-two-tier instrument introduced in this paper, upon further development, will address the need for a tool designed to quickly measure relevant information literacy competencies. With further studies, this instrument could be adjusted to examine the information literacy skills of high school students, or upper-level university students in more areas than just engineering. Future papers will examine the results from a larger data set of firstyear and upper-class engineering students.

A limitation of the study is the low reliability coefficient of the instrument and low discrimination index of some the items. In the light of the item analysis and using the openended responses of the students, further adjustments to the test will be made to overcome these limitations.

\section{Acknowledgement}

This research was carried out under IRB protocol \#1008009557, with financial support from the Purdue College of Engineering's "Engineer of 2020 Seed Grant” program.

\section{References}

1. Shuman, L.J., Besterfield-Sacre, M. \& McGourty, J. The ABET 'Professional Skills'--Can they be taught? Can they be assessed? Journal of Engineering Education 94, 41-55 (2005).

2. Lattuca, L.R., Terenzini, P.T. \& Volkwein, J.F. Engineering Change: A Study of the Impact of EC2000, (ABET, Baltimore, MD, 2006).

3. Holliday, W. \& Li, Q. Understanding the Millenials: Updating Our Knowledge About Students. Reference Service Review 32, 356-366 (2004).

4. Brophy, J. \& Bawden, D. Is Google Enough? Comparison of an Internet Search Engine with Academic Resources. New Information Perspectives 57, 498-512 (2005).

5. Denick, D., Bhatt, J. \& Layton, B. Citation Analysis of Engineering Design Reports for Information Literacy Assessment. in 2010 American Society for Engineerin Education Annual Conference \& Exposition (Lousiville, KY, 2010).

6. Brown, C., Murphy, T.J. \& Nanny, M. Turning Techno-Savvy into Info-Savvy: Authentically Integrating Information Literacy into the College Curriculum. Journal of Academic Librarianship 29, 386-398 (2003).

7. Wertz, R.E.H., Ross, M., Fosmire, M., Cardella, M.E. \& Purzer, S. Do students gather information to support design decisions? Assessment with an Authentic Design Task in First-Year Engineering. in 2011 American Society for Engineering Education Annual Conference \& Exposition (Vancouver, BC, 2011).

8. Katz, I.R. Testing Information literacy in Digital Environments: ETS's iSkills Assessment. Information Techniology and Libraries 26, 3-12 (2007).

9. Center for Assessment and Research \& James Madison University Libraries. Information Literacy Test (Center for Assessment and Research Studies, n.d.).

10. Oakleaf, M. Dangers and Opportunities: A Conceptual Map of Information Literacy Assessment Approaches. Libraries and the Academy 8, 233-253 (2008). 


\section{Appendix - Multiple Choice Assessment Instrument}

\section{Information Literacy, Life-long Learning}

The memo below is written by an engineering student and proposes a solution that would result in energy savings.

To: Purdue University Residence Halls

From: Engineering Consultant Team \#10

Subject: Suggestions for Sustainability in Dorm Rooms

Date: December 1, 2009

The client, Purdue University, is in need of a way to reduce energy consumption in the dorm rooms. Our team has brainstormed several ways to do this and have chosen the best way to increase energy savings and sustainability. More specifically, our goal is reducing the amount of energy used as a result of lighting by $50 \%$.

Our solution is to replace all of the light bulbs in the dorm rooms with compact fluorescent light bulbs. According to Bluejay (2008), compact fluorescent light (CFL) bulbs use 70\% less energy than regular light bulbs. Other resources report 50-80 percent energy savings. However, there is one constraint. This constraint would be the time involved in replacing all the light bulbs. We also assumed that all dorm rooms currently use regular incandescent light bulbs.

After surveying students of one floor of a dormitory, it was found that the average student leaves their overhead lights on for approximately 5 hours a day. This number can be higher and lower depending on the time of the semester. Hence, 5 hours a day is the average for the entire year. We also identified that the average cost of energy per KWH for West Lafayette is 6 cents (dukeenergy.com). We also used the following information for our calculations:

- The lights were on 5 hours a day,

- There are two bulbs per overhead light,

- The bulbs installed are 14 Watts, and

- The average student was in his or her room 200 days a year.

Given this information, we calculated the total cost of using the CFL to be $\$ 840$. Following the aforementioned assumptions and that standard $60 \mathrm{KW}$ light bulbs are used, instead of the 14 Watt CFLs; the total cost would be $\$ 3,600$. This shows that switching to the CFLs would save $\$ 2,760$ a year. The CFL lights would cost on average around $\$ 10$ compared to $\$ 5$ for the incandescent bulbs. We do not expect that the labor for the work would exceed $\$ 2000$. Therefore, the bulbs would more than pay themselves off within one year.

Table 1. Energy Saving Calculations

\begin{tabular}{|l|c|c|c|c|c|}
\hline Type & $\begin{array}{c}\text { Price per } \\
\text { KWH }\end{array}$ & $\begin{array}{c}\text { KW used } \\
\text { per hour }\end{array}$ & $\begin{array}{c}\text { Length of time } \\
\text { lights are used } \\
\text { (hours) }\end{array}$ & $\begin{array}{c}\text { Days lights are used } \\
\text { per year }\end{array}$ & $\begin{array}{c}\text { Total Cost of } \\
\text { Lighting Dorm } \\
\text { Room Per Year }\end{array}$ \\
\hline CFL & $\$ 0.06$ & 14 & 5 & 200 & $\$ 840$ \\
\hline Incandescent & $\$ 0.06$ & 60 & 5 & 200 & $\$ 3,600$ \\
\hline$\$ \$$ Savings & & & & & $\$ 2,760$ \\
\hline
\end{tabular}

\section{References}

1. "Energy Rates." 8 Dec. 2008 http://www.duke-energy.com.

2. "Information on Compact Fluorescent Light Bulbs (CFLs) and Mercury." http://www.energystar.gov/ia/partners/promotions/change_light/downloads/fact_sheet_mercury.pdf.

3. O'neill, Robert. "Green Topics: Incandescent vs. CFL vs. LED Bulb Challenge." Green Topics. 30 Oct. 2008. 8 Dec. 2008 http://greentopics.blogspot.com/2008/10/incandescent-vs-cfl-vs-led-light-bulbs.html.

4. Interviews with students staying in dorms

5. Cardella, M.E., Hoffmann, S.P., Ohland, M.W., \& Pawley, A.L. (2010). Sustaining sustainable design through 'normalized sustainability' in a first-year engineering course. International Journal of Engineering Education.

6. http://michaelbluejay.com/electricity/lighting.html 
Answer the following questions based on the arguments made in this memo. Each question has one best answer.

1. Which one of the following is an assumption made in this memo/report?
a. The CFL bulbs are $70 \%$ more efficient than standard light bulbs.
b. The average cost of energy in KWH for West Lafayette is 6 cents.
c. Students leave their lights on for approximately five hours a day.
d. The average student stays in his or her dorm room 200 days a year.

2. Which one of the following statements used in the memo includes incorrect factual information?
a. Switching to the CFLs would save money.
b. A standard light bulb uses $60 \mathrm{KW}$ per hour.
c. CFL bulbs use $50-80 \%$ less energy than regular bulbs.
d. Lighting can consume more energy than a refrigerator.

3. The statement(s) above is not correct because...

4. Which one of the references is from an unreliable information source?
a. \#1 Energy rates (2008)
b. \#2 Information on Compact Fluorescent Light Bulbs (CFLs) and Mercury
c. \#3 O'neill, Robert (2008)
d. \#4 Interviews
e. \#5 Cardella, et al. (2010)

5. This is not a reliable information source because...

6. Which one of the citations is complete and accurate?
a. \#1 Energy rates (2008)
b. \#2 Information on Compact Fluorescent Light Bulbs (CFLs) and Mercury
c. \#3 O'neill, Robert (2008)
d. \#4 Interviews
e. \#5 Cardella, et al. (2010)

7. What are the strengths of this memo?

a. Gathering and using diverse information

b. Consistency of citations and documentation

c. Evaluating the quality of information gathered

d. Supporting arguments with accurate calculations

8. What are the weaknesses of this memo?

a. The information gathered is too specific

b. There are several scientific and calculation errors

c. Claims are not supported with data or calculations

d. Used unreliable information such as interviews with students

9. What information is missing from this memo that is needed for the authors to make a solid argument?

a. Current utility rates for West Lafayette.

b. Cost of labor to install compact fluorescent bulbs.

c. Lighting spectra of fluorescent and incandescent bulbs.

d. The major manufacturers of compact fluorescent bulbs.

e. The memo contains all the information needed for a solid argument.

10. What is the main point of this memo?

a. Duke Energy charges a lot of electricity.

b. It costs less than $\$ 2000$ to change a light bulb.

c. Students leave the lights on too long in the dorms.

d. Using CFL's will save $\mathbf{5 0 \%}$ or more in lighting costs for the university.

e. Incandescent and fluorescent bulbs use different technologies to produce light. 